Fatma Ceri

Die Bildungsbenachteiligung von Kindern mit Migrationshintergrund 
Migration * Minderheiten * Kulturen

herausgegeben von Guido Schmitt

Band 4 
Fatma Ceri

\title{
Die Bildungsbenachteiligung von Kindern mit Migrationshintergrund
}

\author{
Welche Folgen hat der schulische Umgang \\ mit sprachlichen Differenzen \\ auf die Bildungschancen?
}




\section{Zur Autorin:}

Fatma Ceri, 1977 als zweites Kind einer Migrantenfamilie geboren, absolvierte an der Pädagogischen Hochschule Freiburg ein Studium für Lehramt an Grund- und Hauptschulen mit den Fächern Mathematik, Haushalt und Textil sowie Biologie. Sie beginnt nach der Elternzeit für ihr zweites Kind ihr Referendariat.

\section{Die Deutsche Bibliothek - CIP-Einheitsaufnahme}

Bibliographische Information der Deutschen Bibliothek:

Die deutsche Bibliothek verzeichnet diese Publikation in der

Deutschen Nationalbibliographie; detaillierte bibliographische Daten

sind im Internet über http://dnb.ddb.de abrufbar.

ISBN 978-3-8255-0717-6 ISBN 978-3-86226-347-9 (eBook)

DOI 10.1007/978-3-86226-347-9

\section{ISSN 1434-8896}

Alle Rechte, insbesondere das Recht der Vervielfältigung und Verbreitung sowie der Übersetzung, vorbehalten. Kein Teil des Werkes darf in irgendeiner Form (durch Fotokopie, Mikrofilm oder ein anderes Verfahren) ohne schriftliche Genehmigung des Verlages reproduziert oder unter Verwendung elektronischer Systeme verarbeitet, vervielfältigt oder verbreitet werden.

(C) CENTAURUS Verlags KG, Kenzingen 2008

Satz: Vorlage der Autorin

Umschlaggestaltung: Antje Walter, Titisee-Neustadt

Umschlagabbildung: photocase.com

Satz: Vorlage der Autorin 
Dieses Buch widme ich meinem lieben Ehemann Ercüment und unserer Tochter Neva 


\section{Inhaltsverzeichnis}

1. Einleitung

2. Chancenungleichheit von Migranten im deutschen Bildungssystem 13

2.1. Begriff „Migration“

2.2. Vom Ausländer- zum Migrationskonzept

2.3. Datenlage nach dem Migrationskonzept

2.3.1. Migranten in Deutschland

2.3.2. Migranten in den einzelnen Bundesländern

2.3.3. Altersgruppe der Bevölkerung mit Migrationshintergrund

\subsection{Bildungsbeteiligung von Kindern mit Migrationshintergrund} und die Chancenungleichheiten im deutschen Schulsystem

2.4.1. Verpflichtung und Verantwortung des Schulsystems

2.4.2. Kinder mit Migrationshintergrund im deutschen

Schulsystem

2.4.2.1. Verteilung der Schülerinnen und Schüler mit Migrationshintergrund auf die einzelnen Schularten

2.4.2.2. Selektivität des deutschen Schulsystems

2.4.2.3. Regionale Verteilung

2.4.2.4. Bildungserfolg von deutschen und nicht-deutschen Schülerinnen und Schülern im Vergleich

2.4.2.5. Nationaler Vergleich der erreichten

Schulabschlüsse 
2.5. Übergang der Jugendlichen mit Migrationshintergrund in die Berufsausbildung

2.6. Die Kompetenzen der Kinder mit Migrationshintergrund nach der internationalen Schulleistungsvergleichsstudie PISA

2.6.1. Bildungsbeteiligung von Jugendlichen aus

Migrationsfamilien

2.6.2. Kompetenzerwerb von Jugendlichen mit Migrationshintergrund

2.6.3. Vergleich der Bundesländer nach PISA

3. Ursachen für die Benachteiligung von Kindern und Jugendlichen mit Migrationshintergrund im deutschen Schulsystem

3.1. Außerschulische Aspekte - Merkmale der Migrantenkinder oder ihrer Eltern

3.1.1. Erklärung durch kulturelle Defizite

3.1.1.1. Defizitäre Herkunfts- und Lernkultur

3.1.1.2. Unterschichtskultur als defizitäres

Sozialisationsumfeld

3.1.2. Erklärungen nach dem humankapitaltheoretischen Ansatz

49

3.2. Innerschulische Aspekte - Merkmale der Schule als Institution 54

3.2.1. Systemimmanente und organisationsbezogene Effekte

3.2.2. Benachteiligung aufgrund institutioneller Diskriminierung 55 
3.3. Die Bedeutung der Sprachkenntnisse für die Bildungschancen und den Bildungserfolg

3.3.1. Sprache und Sprachkompetenz

3.3.1.1. Sprachentwicklung und Zweisprachigkeit

3.3.1.2. Die Interdependenzhypothese

3.3.1.3. Die Schwellenhypothese

3.3.2. Der schulische Umgang mit sprachlichen Differenzen

4. Schulische Förderung von Kindern und Jugendlichen mit Migrationshintergrund und Perspektiven und Chancen für ein gerechtes deutsches Schulsystem

4.1. Förderung der Sprachkenntnisse

4.2. Qualifikation des Personals

5. Zusammenfassende Schlussbetrachtung 80

Literaturverzeichnis 